\title{
Upper Gastrointestinal Tract Polyps: What Do We Know About Them?
}

\author{
Kenan Buyukasik ${ }^{1}$, Mert Mahsuni Sevinc ${ }^{1}$, Umut Riza Gunduz ${ }^{2 *}$, Aziz Ari' ${ }^{1}$, \\ Bunyamin Gurbulak $^{1}$, Ahmet Burak Toros ${ }^{3}$, Hasan Bektas ${ }^{1}$
}

\begin{abstract}
Background: This study aimed to evaluate upper gastrointestinal polyps detected during esophagogastroduodenoscopy tests. Materials and Methods: We conducted a retrospective analysis on data regarding 55,987 upper gastrointestinal endoscopy tests performed at the endoscopy unit of Istanbul Education and Research Hospital between January 2006 and June 2012. Results: A total of 66 upper gastrointestinal polyps from 59 patients were analyzed. The most common clinical symptom was dyspepsia, observed in 41 cases $(69.5 \%)$. The localizations of the polyps were as follows: 29 in the antrum $(43.9 \%), 15$ in the corpus $(22.7 \%), 11$ in the cardia $(16.7 \%), 3$ in the fundus $(4.54 \%), 3$ in the second portion of the duodenum $(4.54 \%), 2$ in the bulbus $(3.03 \%)$ and 3 in the lower end of the esophagus (4.54\%). Histopathological types of polyps included hyperplastic polyps (44) $(66.7 \%)$, faveolar hyperplasia $(8)(12.1 \%)$, fundic gland polyps $(4)(6.06 \%)$, squamous cell polyps $(4)(6.06 \%)$, hamartomatous polyps (3) $(4.54 \%)$, and pyloric gland adenoma (3) $(4.54 \%)$. Histopathological analysis of the gastric mucosa showed chronic atrophic gastritis in 30 cases $(50.84 \%)$, HP infection in 33 cases $(55.9 \%)$ and intestinal metaplasia in 19 cases $(32.20 \%)$. In 3 cases with multiple polyps, adenocarcinoma was detected in hyperplastic polyps. Conclusions: Among polypoid lesions of the upper gastrointestinal tract, the most common histological type is hyperplastic polyps. Generally, HP infection is associated with chronic atrophic gastritis and intestinal metaplasia. The incidence of adenocarcinoma tends to be higher in patients with multiple hyperplastic polyps.
\end{abstract}

Keywords: Upper gastrointestinal tract - polyps - gastroscopy - Turkey

Asian Pac J Cancer Prev, 16 (7), 2999-3001

\section{Introduction}

Upper gastrointestinal tract (GIT) polyps are usually asymptomatic. However, they may cause symptoms such as dyspepsia, bleeding, anemia, abdominal pain and gastric outlet obstruction. During endoscopic procedures, they are usually observed at an incidence rate of 2-3\%. Their incidence rate in general population is rather low at less than $1 \%$ (Feldman et al., 2010). The most frequent localization in the stomach appears to be the antrum (58.8\%) (Yoon et al., 2006). Upper GIT polyps can be seen with synchronic or metachronic colon polyps (Hirota et al., 2006). The majority of gastric polyps (70-90\%) are hyperplastic or fundic gland polyps. Hyperplastic and adenomatous polyps are more prevalent in areas where HP infection is common (Archimandritis et al., 1996; Morais et al., 2007). On the other hand, fundic gland polyps are more common in regions of HP eradication (Jalving et al., 2006; Carmack et al., 2009). The presence of H pylori infection is closely related to chronic gastritis which significantly increases the risk of developing peptic ulcer, gastric adenocarcinoma an gastric mucosa-associated lymphoid tissue lymphoma (Demirel et al., 2013).

Gastric adenomatous polyps have potential for malignancy. It was reported that about $11 \%$ of such polyps developed into carcinoma in situ within 4 years of followup (Feldman et al., 2010). After excision, the recurrence rate is $16 \%$ (Hirota et al., 2006).

The purpose of this study was to examine the relationships between demographic characteristics of patients with upper gastrointestinal polyps and localization, histopathological types, HP infection, as well as changes in gastric mucosa and the rate of malignant development, with reference to the current information found in the literature.

\section{Materials and Methods}

We conducted a retrospective analysis on the data regarding 59 patients with polyps [37 females and 22 males with a mean age of 66.79 years, (ranging from 35 to 89 years)] which were detected during routine upper gastrointestinal endoscopy $(55,987$ tests) performed at the endoscopy unit of Istanbul Education and Research 


\begin{tabular}{|c|c|c|c|c|c|c|c|}
\hline $\begin{array}{c}\text { Hyperplastic } \\
\text { (N: 41) }\end{array}$ & $\begin{array}{c}\text { Fundic gland } \\
(\mathrm{N}: 2)\end{array}$ & $\begin{array}{c}\text { Adenomatozis } \\
(\mathrm{N}: 4)\end{array}$ & $\begin{array}{l}\text { Hamartomatous } \\
(\mathrm{N}: 1)\end{array}$ & $\begin{array}{l}\text { s Faveolar } x \\
\text { hiperplasia } \\
\text { (N: 5) }\end{array}$ & $\begin{array}{c}\text { xanthomatous } \\
\text { polyp } \\
(\mathrm{N}: 2)\end{array}$ & $\begin{array}{l}\text { Pyloric gland } \\
\text { adenoma } \\
(\mathrm{N}: 1)\end{array}$ & $\begin{array}{c}\text { Noroendocrine } \\
\text { neoplasia } \\
(\mathrm{N}: 3)\end{array}$ \\
\hline \multicolumn{8}{|l|}{$\overline{\text { Age }}$} \\
\hline 67.2 & 55 & 70.66 & 76 & 60.8 & 73 & 82 & 61 \\
\hline \multicolumn{8}{|l|}{ Gender Female/Male } \\
\hline $24 / 17$ & $1 / 1$ & $3 / 1$ & $1 / 0$ & $4 / 1$ & $1 / 1$ & $1 / 0$ & $3 / 0$ \\
\hline \multicolumn{8}{|l|}{ Single / multiple polyp } \\
\hline $37 / 4$ & $1 / 1$ & $3 / 1$ & $1 / 0$ & $4 / 1$ & $2 / 0$ & $1 / 0$ & $3 / 0$ \\
\hline \multicolumn{8}{|l|}{ Hp prevalance $\mathrm{n}(\%)$} \\
\hline $28(\% 68.29)$ & 0 & 4 & 0 & 0 & 0 & 1 & 0 \\
\hline \multicolumn{8}{|l|}{ Intestinal metaplasia n(\%) } \\
\hline $16(\% 39.02)$ & 0 & 1 & 0 & 2 & 0 & 0 & 3 \\
\hline \multicolumn{8}{|l|}{ Atropic gastrytis $\mathrm{n}(\%)$} \\
\hline $23(\% 56.09)$ & 0 & 1 & 1 & 2 & 0 & 0 & 3 \\
\hline
\end{tabular}

Hospital between January 2006 and June 2012. A total of 66 polyps retrieved from these patients with polypectomy were analyzed in terms of their localization, histopathological characteristics, changes that occurred in gastric mucosa, their relationship with HP infection, and rate of malignant transformation.

All endoscopic procedures were performed with Midazolam (IV) and sedation. The polyps were resected with application of cautery through a snare or biopsy forceps. In addition, at least two antral biopsy specimens were collected from all patients undergoing polypectomy.

\section{Results}

The upper GIT polyps were located in the antrum in 29 patients $(43.93 \%)$, corpus in 15 patients $(22.72 \%)$, cardia in $11(16.66 \%)$, fundus in $3(4.54 \%)$, second portion of the duodenum in $3(4.54 \%)$, bulbus in $3(3.03 \%)$ and lower end of esophagus in 3 patients $(4.54 \%)$. In 7 patients $(11.86 \%)$, multiple polyps were present. Adenocarcinoma was detected in three of the patients with multiple polyps.

In cases with fundic gland polyps, no intestinal metaplasia was detected, while this type was more common in older age groups. 39.02\% of the patients with hyperplastic polyps had intestinal metaplasia. HP incidence was significantly higher in patients with hyperplastic polyps than in those with fundic gland polyps. In $56.09 \%$ of cases with hyperplastic polyposis, chronic atrophic gastritis was present. In 3 patients diagnosed with neuroendocrine neoplasia, chronic atrophic gastritis and intestinal metaplasia were observed in the stomach. However, they had no HP infection.

The demographic data of the patients with polyps, histological types, gastric mucosa and their relationship with HP infection are summarized in Table 1.

\section{Discussion}

Gastric polyps are histologically classified as hyperplastic, adenomatous or inflammatory polyps. The incidence of gastric polyps detected with endoscopic procedures has been reported to range from 2 to $6 \%$ (Carmack et al. 2009; Mansour-Ghanaei et al., 2012). Accounting for $80 \%$ of cases, hyperplastic polyps derive from the tissues lining the inner surface of the stomach, and they are not true neoplasms. There is no connection between these polyps and gastric carcinoma. Further endoscopic monitoring is not indicated in hyperplastic polyps. However, hyperplastic polyps are more likely to coexist with atrophic gastritis, which is generally considered to have precancerous potential. Approximately $10 \%$ of adenomatous polyps contains malignant foci called adenocarcinoma. In addition, $20 \%$ of the patients with benign adenomatous polyps have been reported to have a malignant cancer in another part of their stomach. The incidence of cancer in adenomatous polyps tends to be higher as the size of the polyp increases. Pedunculated lesions smaller than $2 \mathrm{~cm}$ in diameter are not usually malignant. Roughly $10 \%$ of the benign adenomatous polyps may show malignant transformation therefore endoscopic monitoring of patients is recommended after these polyps have been removed by polypectomy (Kokkola et al., 1998; Oberhuber and Stolte, 2000; Mansour-Ghanaei et al., 2013).

The incidence of polyps and histopathological types vary between geographical regions. A retrospective study examining gastric polyps reported that patients diagnosed with gastric polyps ranged from 22 to 87 years of age, while patients over the age of 60 had an increased likelihood of multiple polyps. In this study, the most common type of polyps were hyperplastic polyps (70\%) (Archimandritis et al., 1996).

Hyperplastic polyps are usually associated with HP infection and atrophic gastritis. Hyperplastic and adenomatous polyps are known to be more prevalent in geographical regions where HP infection is common, as compared with fundic gland polyps (Morais et al., 2007). HP infection was found to be protective against the development of fundic gland polyps. Patients with fundic gland polyps were reported to have a low incidence rate of HP infection (Carmack et al. 2009). There are also studies showing that HP eradication therapy may lead to regression of hyperplastic polyps (Ljubicic et al.,1999; Ohkusa et al., 1998). In our study, 39.02\% of the patients with hyperplastic polyps were diagnosed with intestinal metaplasia. HP incidence was found to be significantly higher in patients with hyperplastic polyps than in those with fundic gland polyps.Also three patients had 
noroendocrine neoplasia.

In conclusion, hyperplastic polyps are the most common polyps seen in the upper gastrointestinal tract. In cases with hyperplastic polyps, the incidence of HP infection and concomitant chronic atrophic gastritis and intestinal metaplasia is higher. Faveolar hyperplasia is the second most common and can be regarded as a precursor of hyperplastic polyps. Multiple polyps are more prevalent in patients over age 60 , with an increased cancer rate.

\section{References}

Archimandritis A, Spiliadis C, Tzivras M, et al (1996). Gastric epithelial polyps; a retrospective endoskopic study of 12974 symptomatic patients. Ital J Gastroenterol, 28, 387-90.

Carmack SW, Gentra RM , Schuler CM, Sabortan MH (2009). The current spectrum of gastric polpyps; 1 year national study of over 120000 patients. Am J Gastroenterol, 104, 1524-32.

Demirel BB,Akkas EB, Vural GU (2013). Clinical factors related with helicobacter pylori infection is there an association with gastric cancer history in first-degree family members? Asian Pacific J Cancer Prev, 14, 1797-802.

Hirota WK, Zuckerman MJ, Adler DG, et al (2006). ASGE guideline: the role of endoscopy in the surveillance of premalignant conditions of the upper GI tract. Gastrointest Endosc, 63, 570-80.

Jalving M, Koornsta JJ, Wesseling J, et al (2006). Increased risk of fundic gland polipys during long term proton pump inhibitor therapy. Aliment Pharmacol Ther, 24, 1341-8.

Kokkola A. Sjoblom S, Haapiainen R, et al (1998). The risk of gastric carcinoma and carcinoid tumours in patients with pernicious anemia: a prospective follow-up study. Scand $J$ Gastroenterol, 33, 88-92.

Ljubicic N, Banic M, Kujundzic M, et al (1999). The effect of eradicating Helico- bacter pylori infection on the course of adenomatous and hyperplastic gastric polyps. Eur $J$ Gastroenterol Hepatol, 11, 727-30.

Mansour-Ghanaei F, Sokhanvar H, Joukar F, et al (2012). Endoscopic findings in a mass screening program for gastric cancer in a high risk region-Guilan province of Iran. Asian Pac J Cancer Prev, 13, 1407-12.

Mansour-Ghanaei F, Joukar F, Baghaei SM, et al (2012). Gastric precancerous lesions in first degree relatives of patients with known gastric cancer: a cross-sectional prospective study in guilan province, North of Iran. Asian Pac J Cancer Prev, 13, 1779-82.

Mansour-Ghanaei F, Joukar F, Soati F, et al (2013). Outcome of intestinal metaplasia in gastric biopsy of patients with dyspepsia in guilan province, North Iran. Asian Pac J Cancer Prev, 14, 3549-54.

Morais DJ, Yamanaka A, Zeitune JM, Andreollo NA (2007). Gastric polyps: a retrospective analysis of 26000 digestive endoscopies. Arg Gastroenterol, 44, 14-7.

Oberhuber G, Stolte M (2000). Gastric polps; an update of their pathology and biological signifance. Virchows Arch, 437, 581-90.

Ohkusa T, Takashimizu I, Fujiki K, et al (1998). Disappearance of hyperplastic polyps in the stomach after eradication of Helicobacter pylori . A randomized, clinical trial. Ann Intern Med, 129, 712-5.

Feldman M, Friedman LS, Brandt LJ (2010). Sleisenger and Fordtran's Gastrointestinal and Liver Disease- $9^{\text {th }}$ edition.

Yoon WJ,Lee DH, Jung YJ, et al (2006). Histologic characteristics of gastric polyps in Korcea: emphasis on discrepancy between endoscopic forceps biopsy and endoscopic mucosal resection specimen. World J Gastroenterol, 12, 4029-32. 